\title{
Willingness of Greek general population to get a COVID-19 vaccine
}

\author{
Georgia Kourlaba ${ }^{1,2^{*}}$, Eleni Kourkouni', Stefania Maistreli', Christina-Grammatiki Tsopela', Nafsika-Maria Molocha', \\ Christos Triantafyllou', Markela Koniordou', Ioannis Kopsidas', Evangelia Chorianopoulou', \\ Stefania Maroudi-Manta', Dimitrios Filippou ${ }^{3}$ and Theoklis E. Zaoutis ${ }^{1,4}$
}

\begin{abstract}
Background: Epidemiological data indicate that a large part of population needs to be vaccinated to achieve herd immunity. Hence, it is of high importance for public health officials to know whether people are going to get vaccinated for COVID-19. The objective of the present study was to examine the willingness of adult residents in Greece to receive a COVID-19 vaccine.

Methods: A cross-sectional was survey conducted among the adult general population of Greece between April 28, 2020 to May 03, 2020 (last week of lockdown), using a mixed methodology for data collection: Computer Assisted Telephone Interviewing (CATI) and Computer Assisted web Interviewing (CAWI). Using a sample size calculator, the target sample size was found to be around 1000 respondents. To ensure a nationally representative sample of the urban/rural population according to the Greek census 2011, a proportionate stratified by region systematic sampling procedure was used to recruit particpants. Data collection was guided through a structured questionnaire. Regarding willingness to COVID-19 vaccination, participants were asked to answer the following question: "If there was a vaccine available for the novel coronavirus, would you do it?"

Results: Of 1004 respondents only $57.7 \%$ stated that they are going to get vaccinated for COVID-19. Respondents aged $>65$ years old, those who either themselves or a member of their household belonged to a vulnerable group, those believing that the COVID-19 virus was not developed in laboratories by humans, those believing that coronavirus is far more contagious and lethal compared to the H1N1 virus, and those believing that next waves are coming were statistically significantly more likely to be willing to get a COVID-19 vaccine. Higher knowledge score regarding symptoms, transmission routes and prevention and control measures against COVID-19 was significantly associated with higher willingness of respondents to get vaccinated.
\end{abstract}

Conclusion: A significant proportion of individuals in the general population are unwilling to receive a COVID-19 vaccine, stressing the need for public health officials to take immediate awareness-raising measures.

Keywords: Vaccine hesitancy, COVID-19, Europe, Vaccine coverage

\footnotetext{
* Correspondence: g.kourlaba@cleoresearch.org; kurlaba@gmail.com

${ }^{1}$ Center for Clinical Epidemiology and Outcomes Research (CLEO), Athens,

Greece

${ }^{2}$ ECONCARE LP, Athens, Greece

Full list of author information is available at the end of the article
}

(c) The Author(s). 2021 Open Access This article is licensed under a Creative Commons Attribution 4.0 International License, which permits use, sharing, adaptation, distribution and reproduction in any medium or format, as long as you give appropriate credit to the original author(s) and the source, provide a link to the Creative Commons licence, and indicate if changes were made. The images or other third party material in this article are included in the article's Creative Commons licence, unless indicated otherwise in a credit line to the material. If material is not included in the article's Creative Commons licence and your intended use is not permitted by statutory regulation or exceeds the permitted use, you will need to obtain permission directly from the copyright holder. To view a copy of this licence, visit http://creativecommons.org/licenses/by/4.0/. 


\section{Background}

On March 11, 2020, World Health Organization (WHO) described the spread of corona-virus disease 2019 (COVID-19) as a pandemic. COVID-19, caused by severe acute respiratory syndrome corona-virus 2 (SARS$\mathrm{CoV}-2$ ). Currently scientists found that the virus stains in Italy and some other countries are different in Wuhan, and later on these virus strains were found existing earlier before the virus detected in Wuhan, suggesting possible multi-point transmission of the SARS-CoV-2 [1, 2]. COVID-19 has expanded internationally reaching 66, 243,918 confirmed cases and 1,528,984 deaths worldwide by December 8th, 2020 [3]. Beyond the health crisis, the outbreak of the pandemic has disrupted the financial and social systems of most countries increasing poverty and wealth inequality $[4,5]$.

Greece reported its first confirmed case on February 26th, 2020 [6]. Up until December 8th, 116,721 people have been diagnosed with COVID-19 and 3092 have died [6]. The Greek Government preemptively announced a series of strict measures, including the early adoption of a lockdown (in mid-March), and immediately started a nation-wide public information campaign regarding COVID-19 prevention emphasizing the importance of adopting disease control measures during the lockdown in order to limit the spread of COVID-19 [7]. These measures led Greece to the lowest number of 30-day mortality per million population after Norway and Finland. In contrast, other Southern Europe countries with similar statistics to Greece regarding Gross Domestic Health Expenditure and age distribution, but which delayed initiating lockdown, suffered some of the highest losses from the pandemic [8].

To curtail the spread of the novel corona-virus, pharmaceutical companies and academic institutions globally are working to develop a vaccine. According to the WHO, nearly 180 vaccine candidates are being tested around the world, but none has yet completed clinical trials, at the time of writing. Just one vaccine developed by the Gamaleya Research Institute in Moscow was approved by the Ministry of Health of the Russian Federation on August 11th but it has not launched Phase III of clinical trial $[9,10]$. Researchers estimate that a vaccine is likely to become widely available by mid-21, approximately $12-18$ months after SARS-CoV-2 first appeared [10].

It is widely known that the effectiveness of a COVID19 vaccine depends on adequate uptake [11, 12]. Based on the currently available epidemiological data, SARS$\mathrm{CoV}-2$ is a highly transmissible virus and in order to break the chain of transmission, at least $55-82 \%$ of the population need to be vaccinated to achieve herd immunity [13]. However, there is a growing body of evidence declaring that even nowadays, low vaccination rates have remained an issue of concern while vaccine hesitancy has become more prevalent [14, 15]. Compliance with the anti-H1N1 vaccine during the 2009 influenza pandemic was very low worldwide and particularly in Europe $[16,17]$. The WHO has named vaccine hesitancy as one of the top 10 threats to global health, in 2019 [18]. As such, the next challenge that public health officials will have to overcome regarding COVID-19 is to achieve a high vaccination rate among the public. For this reason, it is important to investigate whether or not people are willing to get vaccinated.

To the best of our knowledge, limited data are available in the international literature regarding the willingness of public to receive a COVID-19 vaccine $[12,13$, 19-22]. A multi-country European study showed that $73.9 \%$ of the participants would be willing to get vaccinated against COVID-19 if a vaccine would be available [12]. Greece, which managed to keep COVID-19 deaths incredibly low and presented as a success story worldwide, did not participate in this European study and as such no data are available regarding the willingness of Greek adult population to be vaccinated.

Hence, the objectives of this study were to: (1) examine the extent to which adults in Greece are willing to receive a COVID-19 vaccine if one was to become available and (2) determine whether socio-demographic, clinical factors as well as knowledge, attitudes and practices (KAP) of adult population against COVID-19 are associated with their willingness.

\section{Methods}

\section{Study design and data collection}

A nationwide cross-sectional survey was conducted in Greece, between April 28, 2020 to May 03, 2020 (last week of lockdown) with a primary objective of assessing the knowledge, attitudes and practices (KAP) of adult population against COVID-19, using a mixed methodology for data collection: Computer Assisted Telephone Interviewing (CATI) and Computer Assisted web Interviewing (CAWI). To calculate the sample size for this survey, we hypothesized that at a $99 \%$ confidence interval, $50 \%$ of the respondents would have a satisfactory knowledge level of COVID-19 at a margin of error $\pm 5 \%$. Using a sample size calculator, the target sample size was found to be around 1000 respondents. To ensure a nationally representative sample of the urban/rural population according to the Greek census 2011 (www. statistics.gr), a proportionate stratified by region random sampling procedure was used to recruit participants. Half of the total target sample size was met by CATI (502 interviews) and the other half (502 interviews) by CAWI. For CATI, a random-digit dialled (RDD) sample of 9977 landline-telephone households was conducted, $74 \%$ of whom were excluded due to unavailability (e.g. 
no answer, busy etc.) but $26 \%$ of whom (2597) led to handled calls. Of those 2597, 1434 refused to participate in this survey, 50 asked for the interview to be terminated before screening was complete, 219 did not meet an age criterion, 228 calls were reached businesses/commercial spaces instead of housholds and 142 communications were not possible. To complete 502 interviews with the CAWI method, 1497 invitations were sent to adults. The response rate for CATI method was $25 \%$, and for CAWI method $33.5 \%$.

To ensure the external validity and the greater generalizability of the study, survey weights were used to adjust for differences in age and gender distribution between survey sample and country population as obtained from the census 2011 (www.statistics.gr). The survey weights were calculated with the rake method (also known as "rim").

Prior to completion of the survey, an informed oral consent procedure was followed. The study protocol was not submitted to the ethical committee of any institution for approval, since according to the Greek legislation (Law 2328/1995, Presidential Decree 310/1996, Law $3603 / 2007$, Law 2472/1997, Law 3471/2006) there is no need for ethics approval in telephone and internet surveys such as the one presented here (Association of Opinion Polls and Survey Organizations - www.sedea. gr).

\section{Questionnaire development}

A structured questionnaire was developed in the Greek language to collect data [see Additional file 1]. This questionnaire consisted of four main themes, as follows: 1) demographics, which surveyed participants' sociodemographic information; 2) knowledge about COVID19 ; 3) attitudes toward COVID-19; and 4) practices to control COVID-19. The survey took $9-12 \mathrm{~min}$ to be completed. The questionnaire was pre-validated by three independent reviewers, and a pre-test study was conducted with 6 individuals. The responses from the pretest were not included in the analyzed data.

To measure knowledge about COVID-19, 23 questions were used. A total knowledge score ranging from 0 to 23 was calculated assigning 1 point to each correct answer. The answers considered correct per question are presented in additional file 2 . Higher score indicating better knowledge of COVID-19. The internal consistency of the questions used in the total score was assessed using Cronbach's alpha coefficient that was found to be 0.580 , indicating "poor" internal reliability. Participants were also asked to state how they received information about COVID-19.

Attitudes towards COVID-19 were measured through 8 questions and practices relevant to COVID-19 control were measured through 7 questions. Among the practices assessed was the willingness of respondents to receive a COVID-19 vaccine when it is to be available. To be more specific, participants were asked to answer the following question: "If there was a vaccine available for the novel coronavirus, would you do it?", and the three potential answers were "yes", "no" and "not sure".

\section{Statistical analysis}

Participant's responses are presented with absolute and relative frequencies (\%), whereas knowledge score is presented with median and interquartile range (IQR). Chisquare test of independence was applied to identify possible factors (demographics, knowledge, attitudes and practices against coronavirus) associated with participant's intension to be vaccinated against COVID-19 if a vaccine was available. Multiple logistic (stepwise) regression was performed to identify independently associated factors with the willingness of Greek adult population to be vaccinated against COVID-19. Factors found to be significantly associated with willingness at a univariate level were entered in a multiple logistic regression. In case of factors found to be strongly correlated (i.e. age and vulnerable group), one of these were selected to be entered in the multiple logistic regression model to avoid collinearity issues. Results are presented with Odds Ratios (OR) and 95\% Confidence intervals (CI). The level of statistical significance was set to $5 \%$. Analysis was conducted with SPSS statistical package v.25.

\section{Results}

\section{Characteristics of participants}

In total of 1004 respondents recruited in the survey, the mean age was 41.7 years (SD: 17.7). Of all respondents, $51.0 \%$ were female, $59.8 \%$ had received college or above education, $63.8 \%$ were married or cohabiting, and $52.0 \%$ reported that they worked before the COVID measures were taken. Almost $35.0 \%$ of respondents reported that they belong to a vulnerable group and $41.2 \%$ reported that they have a member of their household belonging to a vulnerable group (Table 1).

\section{Factors associated with willingness to receive a COVID-19 vaccine}

In total, $57.7 \%(n=579)$ of respondents stated that they are going to get vaccinated for COVID-19 when a vaccine is available, while $26.0 \%(n=261)$ stated that they are unwilling to receive a COVID-19 vaccine and $16.3 \%$ $(n=164)$ named that they are unsure.

Willingness to receive a COVID-19 vaccine by socio-demographic characteristics is presented in Table 1. It was found that respondents aged more than 65 years old [OR (95\% CI): 3.65 (2.57-5.17)], married/cohabiting [OR (95\% CI): 1.36 (1.02-1.81)] and divorced/widowed [OR $(95 \%$ CI): 1.64 (1.01- 
Table 1 Associations between demographic characteristics and willingness of respondents to get vaccinated for COVID-19 in Greece

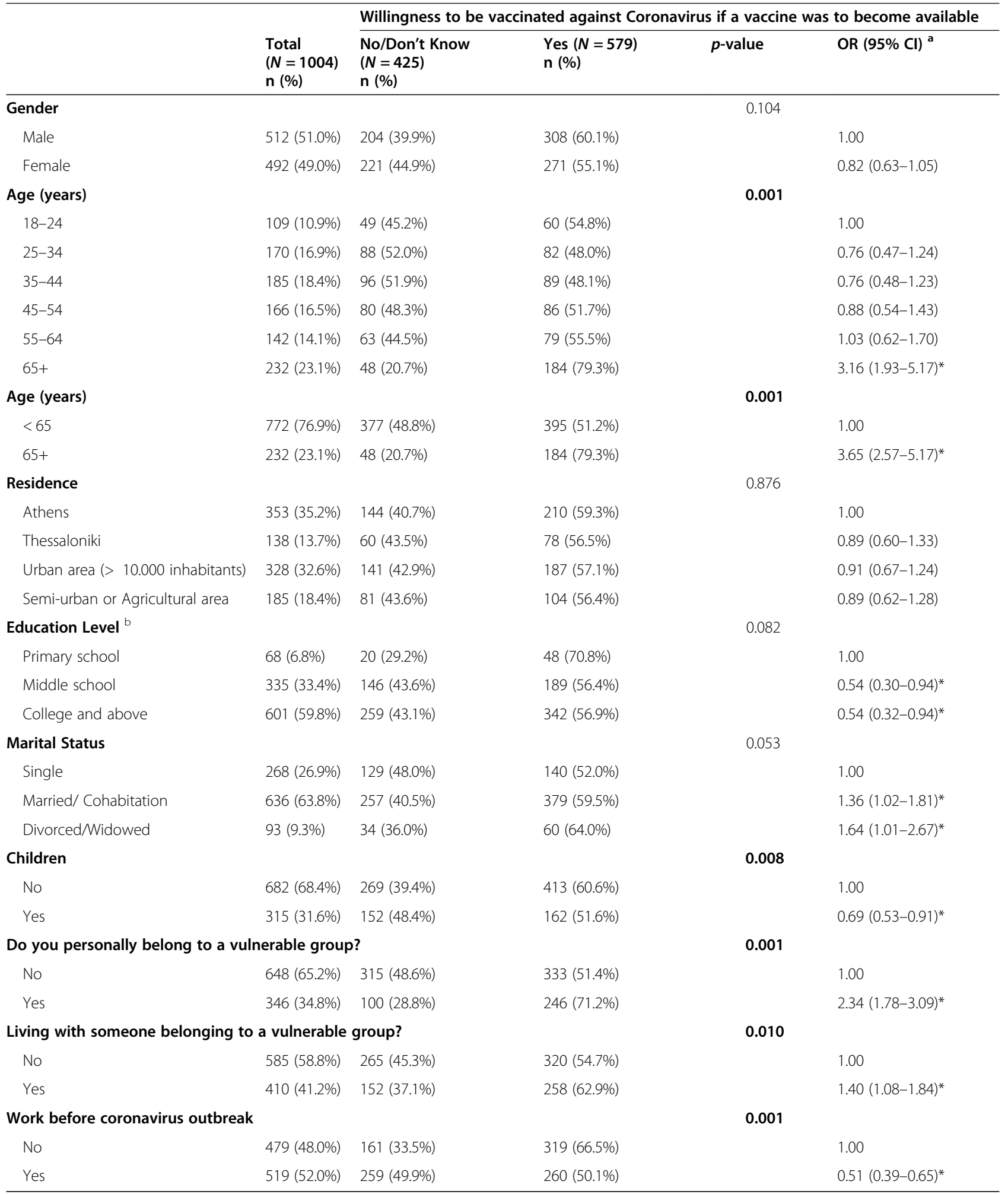

OR Odds Ratio, $\mathrm{Cl}$ Confidence Interval

${ }^{*} p<0.05$

a Results from univariate logistic regression models

${ }^{b}$ Primary school, a school for children between the ages of about five and eleven; Middle school, is the next step up from primary school (ages 12 to 18 ) 
Table 2 Associations between knowledge against Corona Virus and willingness of respondents to get vaccinated for COVID-19 in Greece

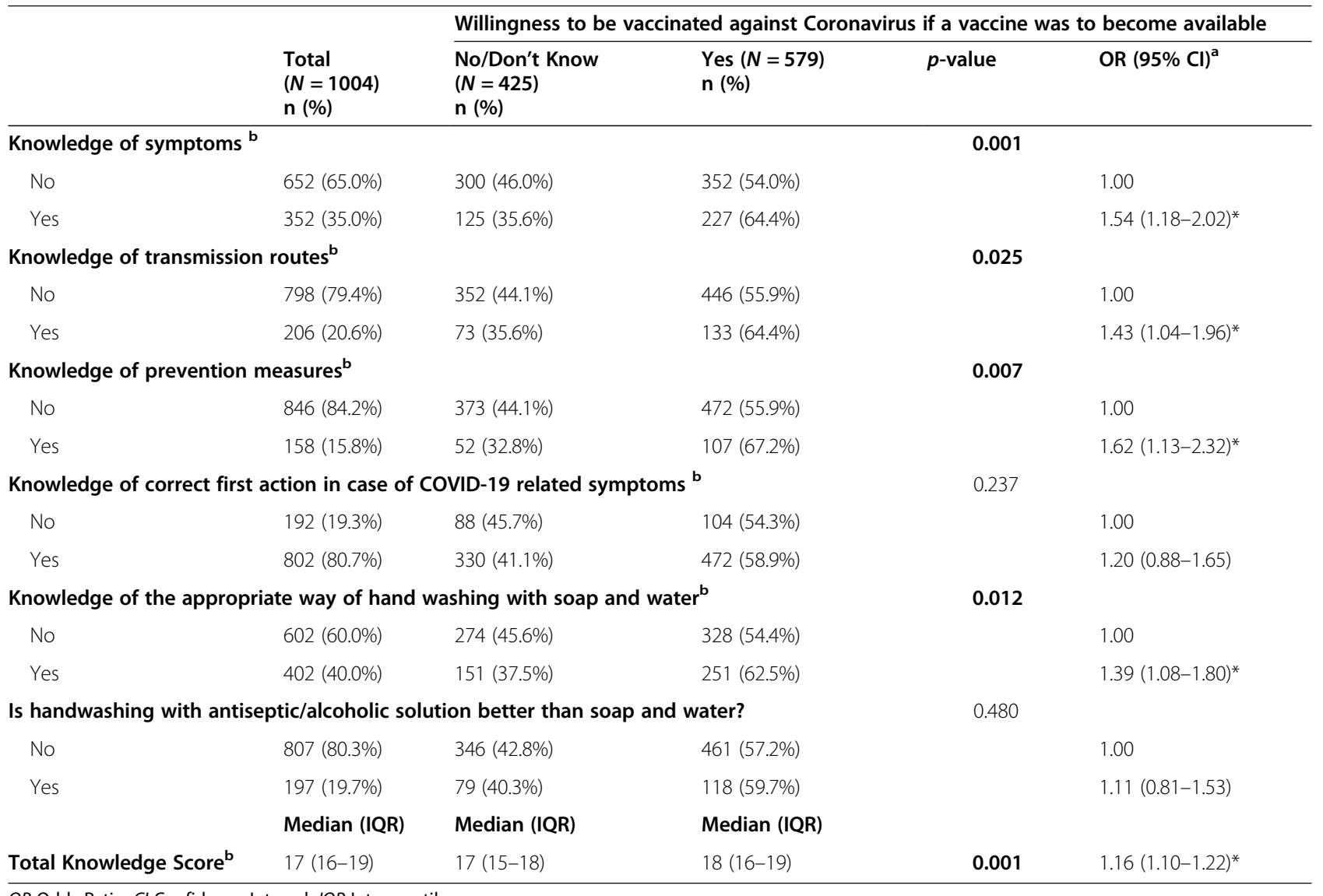

OR Odds Ratio, $\mathrm{Cl}$ Confidence Interval, IQR Interquartile range ${ }^{*} p<0.05$

${ }^{a}$ Results from univariate logistic regression models

${ }^{b}$ As defined in Additional file 2

2.67)], those who did not work before lock-down [OR (95\% CI): $1.96(1,54-2.56)]$, those who belonged to a vulnerable group [OR (95\% CI): 2.34 (1.78-3.09)], those who have a member of their household belonging to a vulnerable group [OR (95\% CI): 1.40 (1.081.84)] and those with no children [OR (95\% CI): 1.45 (1.09-1.89)] over their counterparts were statistically significantly more likely than their counterparts to be willing get a future COVID-19 vaccine.

Table 2 presents the association between knowledge of respondents regarding symptoms, transmission routes and prevention and control measures against COVID-19 and their willingness to get vaccinated when the vaccine is to be available. Respondents reported correctly the 5

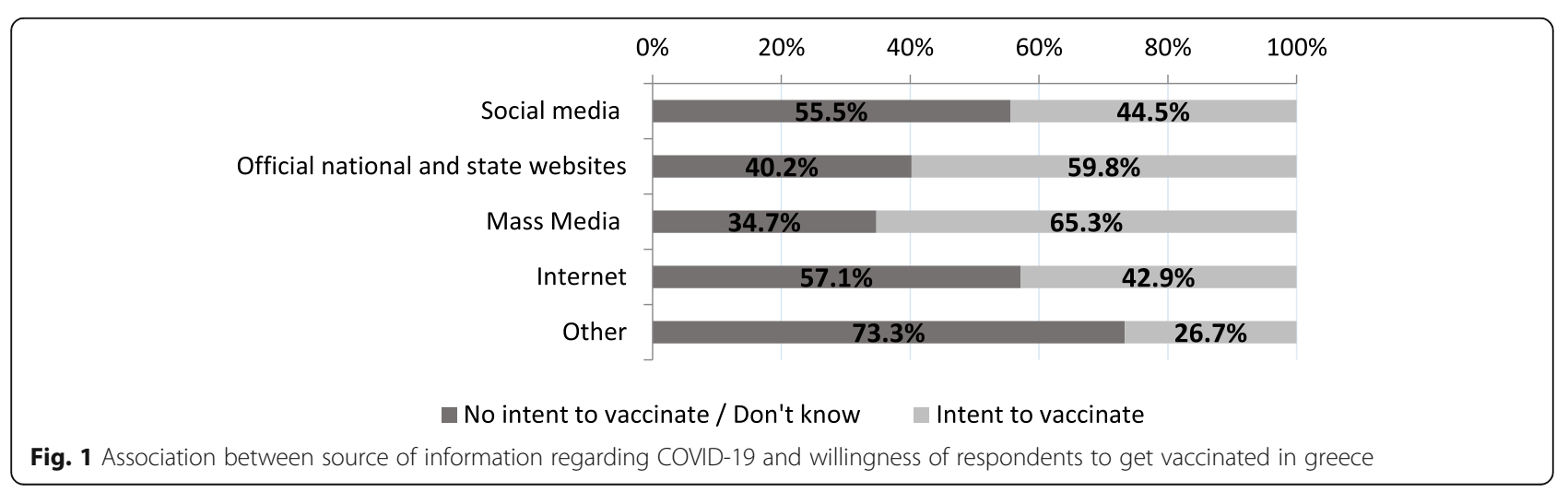


most common symptoms of COVID-19 [OR (95\% CI): $1.54(1.18-2.02)]$, those provided the correct answer in all questions regarding the transmission routes [OR (95\% CI): 1.43 (1.04-1.96)] and those found to know the appropriate control and prevention measures [OR (95\% $\mathrm{CI}): 1.62(1.13-2.32)]$ as well as those knowing the appropriate way of handwashing with soap and water [OR (95\% CI): 1.39 (1.08-1.80)] were statistically significantly more likely by $54,43,62$ and $39 \%$, respectively, to be willing to get vaccinated for COVID-19 (Table 2). Moreover, it was found that the source used by respondents to get informed regarding COVID-19 was significantly associated with their willingness to receive a COVID-19 vaccine $(p<0.001)$. More specifically, respondents informed by mass media and official national and state websites were more likely to be willing to get vaccinated over those informed by social media, internet, or other sources (Fig. 1).

Table 3 presents the association between the attitudes and practices of the Greek adult population regarding COVID-19 and their willingness to get vaccinated for COVID-19 when a vaccine is to be available. It was found that respondents believing that the COVID-19 virus was not developed in laboratories by humans [OR (95\% CI): 4.00 (2.86-5.56)], those believing that coronavirus is far more contagious [OR (95\% CI): 2.50 (1.813.44)] and lethal compared to the H1N1 virus [OR (95\% CI): $2.73(2.05-3.62)]$, those believing that next waves are coming [OR (95\% CI): $1.66(1.25-2.21)]$ and those not believing that the spread of COVID-19 will be eliminated when a large percentage of the population has become infected [OR (95\% CI): $3.57(2.56-5.00)]$ were

Table 3 Associations between attitudes \& practices and willingness of respondents to get vaccinated for COVID-19 in Greece

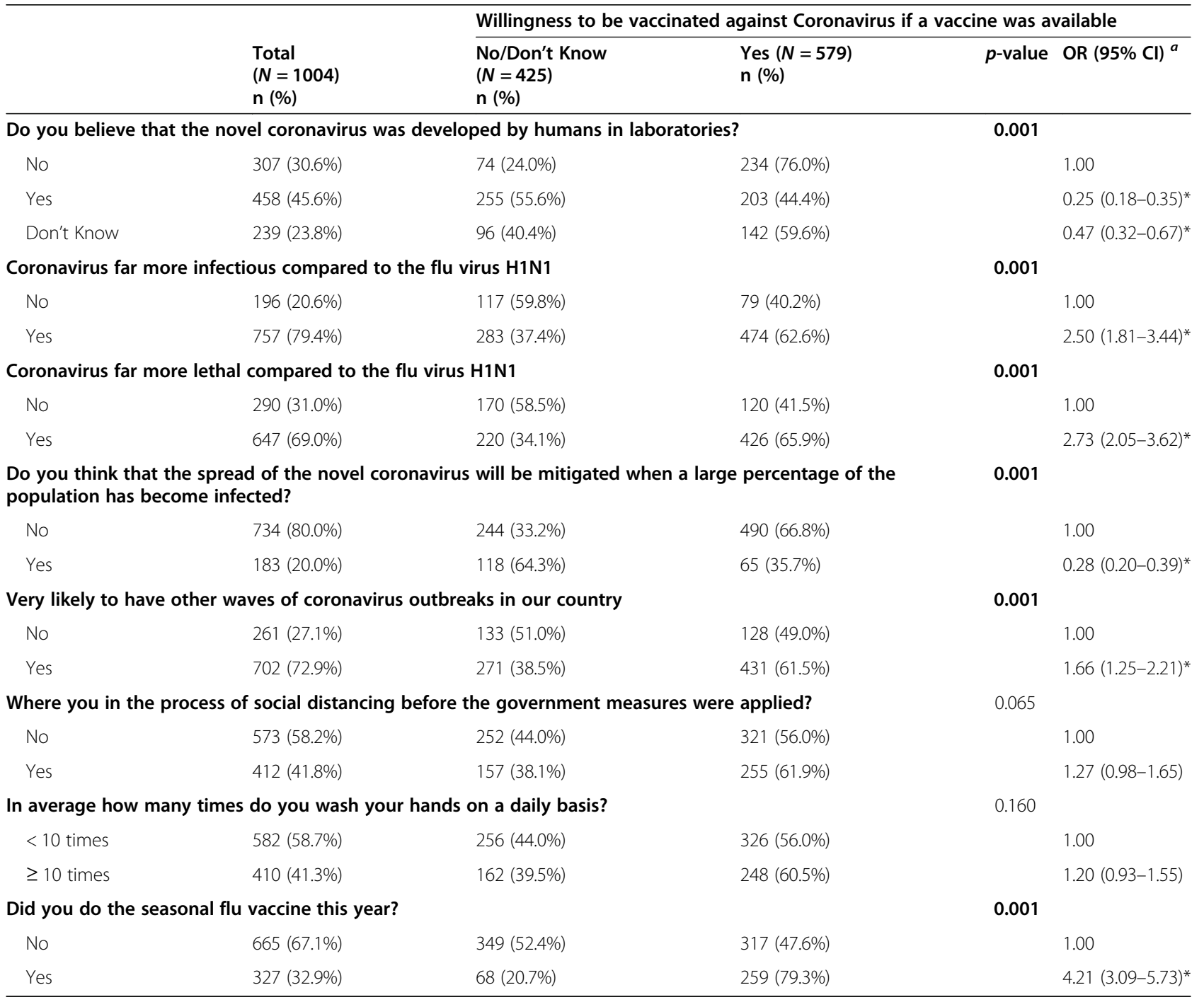

OR Odds Ratio, $\mathrm{Cl}$ Confidence Interval

${ }^{*} p<0.05$

${ }^{a}$ Results from univariate logistic regression models 
statistically significantly more likely to be willing to receive a COVID-19 vaccine compared to their counterparts. Moreover, respondents who had been vaccinated for seasonal flu were significantly more likely to be willing to get vaccinated for COVID-19 [OR (95\% CI): 4.21 (3.09-5.73)] (Table 3).

Multiple logistic regression model (Table 4) revealed that those belonging to a vulnerable group were 37\% more likely to get vaccinated for COVID-19 than those who were not [OR $(95 \% \mathrm{CI})$ : 1.37(1.01-1.94)]. Those who were working before coronavirus outbreak were $38 \%$ less likely to get vaccinated for COVID-19 than those who were not [OR (95\% CI): 0.62(0.44-0.89)]. One-point increase in participant's knowledge score indicated a $12 \%$ increase in the willingness of respondents to receive the COVID-19 vaccine [OR $(95 \%$ CI): 1.12(1.05-1.20)]. Those believing that the novel coronavirus is more lethal than flu and those believing that a new outbreak is coming were 70 and $49 \%$ more likely, respectively, to get vaccinated for COVID-19 [OR (95\% CI): $1.70(1.19-2.44)$ and OR (95\% CI): 1.49(1.03-2.17), respectively]. On the contrary, those believing that the coronavirus was developed by humans in laboratories and those believing that coronavirus will be eliminated when a large percentage of the population will be infected were 73 and $66 \%$ less likely, respectively, to be willing to get vaccinated for COVID-19 [OR (95\% CI): $0.27(0.18-0.39)$ and OR (95\% CI): $0.34(0.23-0.51)$, respectively].

A sensitivity analysis was also conducted adding respondent's that were unsure about receiving a COVID19 vaccine with those that were positive. No significant differences regarding the aforementioned results were detected.

\section{Discussion}

In the race to stop the novel coronavirus that has killed more than half a million people and crippled economies across the globe, many companies and academic institutions are working to develop a vaccine. The effectiveness of the upcoming vaccine depends on the population coverage, since in the case of a low vaccination rate, herd immunity will not be developed, and the most vulnerable population groups will not be protected. As such, it is important to understand beforehand the public's intention to get vaccinated for COVID-19, so that public health officials have the time to design and implement targeted interventions to raise the awareness of general population about the importance of vaccination. After all, hesitancy implies that minds can be

Table 4 Impact of factors on participant's intension to vaccinate against Coronavirus

\begin{tabular}{|c|c|c|}
\hline & OR $(95 \% \mathrm{Cl})$ & $p$-value \\
\hline \multicolumn{3}{|l|}{ Enter Logistic Regression } \\
\hline \multicolumn{3}{|l|}{ Education Level (Reference: Primary school) } \\
\hline Middle school & $0.63(0.29-1.35)$ & 0.232 \\
\hline College and above & $0.64(0.30-1.37)$ & 0.249 \\
\hline \multicolumn{3}{|l|}{ Marital Status (Reference: Single) } \\
\hline Married/ Cohabitation & $1.04(0.70-1.57)$ & 0.833 \\
\hline Divorced/Widowed & $1.12(0.58-2.16)$ & 0.735 \\
\hline Having Children & $0.88(0.61-1.28)$ & 0.513 \\
\hline Belonging to a vulnerable group & $1.37(1.01-1.94)$ & 0.047 \\
\hline Working before coronavirus outbreak & $0.62(0.44-0.89)$ & 0.010 \\
\hline Knowledge Score $^{a}$ & $1.12(1.05-1.20)$ & 0.001 \\
\hline \multicolumn{3}{|l|}{ Source of Info (Reference: Social Media) } \\
\hline Official national and state websites & $1.45(0.81-2.59)$ & 0.214 \\
\hline Mass Media & $1.46(0.86-2.48)$ & 0.156 \\
\hline Internet & $0.65(0.34-1.24)$ & 0.189 \\
\hline \multicolumn{3}{|l|}{ Belief that coronavirus was developed by humans in laboratories (Reference: No) } \\
\hline Yes & $0.27(0.18-0.39)$ & 0.001 \\
\hline Don't Know & $0.40(0.25-0.65)$ & 0.001 \\
\hline Belief that coronavirus far more lethal compared to the flu virus $\mathrm{H} 1 \mathrm{~N} 1$ & $1.70(1.19-2.44)$ & 0.004 \\
\hline Belief that coronavirus will be eliminated when a large percentage of the population will be infected & $0.34(0.23-0.51)$ & 0.001 \\
\hline Belief that new coronavirus outbreak is very likely & $1.49(1.03-2.17)$ & 0.036 \\
\hline
\end{tabular}

OR Odds Ratio, $\mathrm{Cl}$ Confidence Interval

${ }^{a}$ As defined in Additional file 2 
swayed towards acceptance, if presented with the right information.

In this context, the objective of this nationwide crosssectional survey conducted in Greece, was to assess the willingness of adult general population to receive a COVID-19 vaccine when it is to be available as well as factors that might affect their willingness. To the best of our knowledge, this study is the first one conducted in Greece and its results are expected to have a great impact on decisions taken by public health officials.

Our results revealed that over two out of five individuals were unwilling or unsure about receiving a COVID19 vaccine and only $57.7 \%$ stated that they will get vaccinated. The percentage of individuals willing to get vaccinated is not large enough to achieve herd immunity either through vaccination or prior infection transmission based on the estimates of the basic reproduction number $\left(R_{0}\right)[23,24]$. Comparing the willingness rate of our study with that of similar studies conducted in the UK (76.9\%) [13] or other European countries (ranged from 62 to $80 \%$ ) [12], it seems that Greek people are more hesitant against COVID-19 vaccine compared to other European populations. A similar variability across countries had been observed in 2009 for the acceptance of H1N1 influenza pandemic vaccine with this rate ranging between 8 and $67 \%$ and with Greeks reporting lower acceptance rates (ranged from 9.1 to $22.9 \%$ depending on the week of the survey) compared to other European populations [25]. In case that willingness rates and as such vaccination rates remain low, pandemic will continue to have negative effects on population's health and country's economy. In this context, there is an urgent need for an awareness campaign to be designed and implemented by Greek public health officials aiming to increase acceptance rates for COVID-19 vaccine by the Greek general population.

Vaccine hesitancy is a multifaceted, complex issue rooted in multiple values: particularly liberty, risk perception, and distrust. The hesitancy of general population against COVID-19 vaccine could be explained by concerns about the safety and effectiveness of the vaccine or belief that the individuals are not at risk of becoming ill, reasons provided by Greek people to justify their hesitancy over H1N1 flu vaccine [17]. Available data from the previous pandemic of H1N1 indicate that the actual intention of vaccination could be different when a vaccine is available [26]. It is remarkable that in 2009 only a small percentage of approximately $3 \%$ of the entire Greek population ended up receiving a vaccination by the end of December 2009 (4 months after the release), one of the lowest in the European Union [27]. Fortunately, studies have shown that vaccination coverage rates increased over time [28].
Drivers of vaccine hesitancy rely heavily on both belief systems and personal experiences. Our results indicate that specifically socio-demographic categories and medical history affects the willingness to vaccinate for COVID-19 or not. It was found that people aged over than 65 years old or people who belonged to or had a household member belonging to a vulnerable group were statistically significantly more likely to be willing to have a COVID-19 vaccine. Our results are not in line with the findings of similar studies conducted in UK [13] and in France [29]. In the UK study, willingness was not affected by the increased risk of COVID-19 while in France people aged older than 75 years were reluctant to get vaccinated. Our study identified individuals with a lower educational background as the ones more likely to get vaccinated for COVID-19 while studies in UK [13] and Australia [19] demonstrated the opposite. The aforementioned findings indicate that younger people, individuals not belonging to vulnerable groups or not having a vulnerable family member and those with higher educational background could be a target population in educational campaigns about vaccine safety and efficacy since that are currently hesitant to get vaccinated.

Moreover, respondents that had not been vaccinated for seasonal flu and those believing that the coronavirus was man-made in a laboratory were significantly more likely to be negative towards getting vaccinated for COVID-19. This has been previously described by Neumann-Bohme et all [12] who identified concerns about side effects and safety of the vaccine, general rejection of vaccines and beliefs of conspiracy theories as reasons for not wanting to vaccinate. It has also been previously shown that people are more likely to reject new vaccines than familiar ones [30]. It is imperative that the above reasons are taken into consideration in local public health officials' strategies and addressed explicitly in public communication campaigns.

Public awareness campaigns tailored to specific community needs have proven most effective in raising vaccination rates for other outbreaks [31]. Our study revealed that among Greek citizens more knowledgeable respondents on the virus's transmission routes and prevention measures were more likely to get vaccinated. Regarding the source of information, respondents informed by social media, internet, or other sources were less willing to get vaccinated, indicating that social media can be a source of false information. Emerging evidence suggests that correcting misinformation on social media may be effective in changing health beliefs [32].

This study has both strengths and limitations. The strength of this study lies in its study design. In previous KAP studies, data collection was conducted using online self-reported questionnaires that have the disadvantage 
of limiting the participation of vulnerable groups, such as illiterate and rural people, without access to the internet and online health information resources. In our survey, a mixed methodology for data collection was used (CATI and CAWI) ensuring a random sample with greater generalizability in terms of age, gender and residence area. It should be mentioned that, according to the international bibliography, this is the first KAP study that conducted in Europe, contributing to the determination of the knowledge, perceptions and practices of the general population of a European country with different culture and way of life comparing with a country from another continent. Moreover, this is the first study in a nationally representative sample of the urban/rural population that demonstrated public's willingness to receive COVID-19 vaccine if one was to become available.

Our study has also limitations. This was a cross sectional study so it depicts a picture of the community response at the point of the study. The real intention of vaccination against COVID-19 could be different when the vaccine is available. Secondly, as this study used selfreported data, it is possible that participants may have answered questions based on what they perceive to be expected of them (reporting bias) [33]. Furthermore, given that the primary objective of the present survey was to assess KAP of general population against COVID-19, we haven't collected data regarding the reasons of acceptance, hesitancy and unwillingness to do the vaccine.

\section{Conclusions}

In summary, almost half of adult population in Greece seems to be hesitant against the SARS-CoV-2 vaccine when it becomes available. Younger people, individuals not belonging to vulnerable groups or not having a vulnerable family member, those informed by social media, internet, or other non-official sources, people with the perception that the coronavirus was man-made in a laboratory could be potential target groups for interventions aiming to increase public's awareness regarding vaccination. This study is expected to provide useful insights to government agencies, health care workers and other authorities to mitigate the impact of vaccine hesitancy. Further studies need to be conducted to assess the change in the public's willingness to be vaccinated as clinical trials for vaccine development progress to completion.

\section{Supplementary Information}

The online version contains supplementary material available at https://doi. org/10.1186/s41256-021-00188-1.

Additional file 1.

Additional file 2.

\section{Abbreviations}

COVID-19: Coronavirus Disease 2019; CATI: Computer Assisted Telephone Interviewing; CAWI: Computer Assisted Web Interviewing; KAP: Knowledge, Attitudes, and Practices; IQR: interquartile range; OR: Odds Ratios;

$\mathrm{Cl}$ : Confidence interval

\section{Acknowledgments}

Not applicable.

\section{Authors' contributions}

All authors contributed extensively to the work presented in this paper. All authors discussed the results and implications and commented on the manuscript at all stages. G. K, M. K, S.M-M and T.E.Z. designed the study. G. K, N-M.M and E. K carried out the statistical analysis of the data. E. C, I. K, S. M, M. K, C-G.T and D. F edited the manuscript. G. K and C. T wrote the manuscript. T.E.Z supervised the study and edited the final draft of the manuscript. The author(s) read and approved the final manuscript.

\section{Funding}

None.

Availability of data and materials

The datasets used and/or analyzed during the current study are available from the corresponding author on reasonable request.

\section{Ethics approval and consent to participate}

Prior to completion of the survey, all patients were informed about the purpose of the study, were assured abouth the confidentiality and anonymity of the answers told they could terminate the interview at any time. According to the Greek legislation (Law 2328/1995, Presidential Decree 310/1996, Law 3603/2007, Law 2472/1997, Law 3471/2006) there is no need for ethics approval in telephone and internet surveys such the one presented here (Association of Opinion Polls and Survey Organisations www.sedea.gr). Therefore, the study protocol was not submitted to the ethical committee of any institution for approval.

Consent for publication

Not applicable.

\section{Competing interests}

The authors declare that they have no competing interests.

\section{Author details}

${ }^{1}$ Center for Clinical Epidemiology and Outcomes Research (CLEO), Athens, Greece. ${ }^{2}$ ECONCARE LP, Athens, Greece. ${ }^{3}$ Department of Anatomy and Surgical Anatomy, Medical School, National and Kapodistrian University of Athens, Athens, Greece. ${ }^{4}$ Division of Infectious Diseases, The Children's Hospital of Philadelphia, Perelman School of Medicine at the University of Pennsylvania, Philadelphia, USA.

Received: 6 November 2020 Accepted: 21 January 2021

Published online: 29 January 2021

\section{References}

1. Apolone G, Montomoli E, Manenti A, Boeri M, Sabia F, Hyseni I, et al. Unexpected detection of SARS-CoV-2 antibodies in the prepandemic period in Italy. Tumori. 2020. https://doi.org/10.1177/0300891620974755.

2. La Rosa G, Mancini P. Bonanno Ferraro G, Veneri C, laconelli M, Bonadonna $L$, et al. SARS-CoV-2 has been circulating in northern Italy since December 2019: evidence from environmental monitoring. Sci Total Environ. 2021;750: 141711 .

3. Weekly operational update on COVID-19 - 7 December 2020. https://www. who.int/publications/m/item/weekly-operational-update-on-covid-19\%2D\%2 D-7-december-2020. Accessed 8 Dec 2020.

4. Nicola M, Alsafi Z, Sohrabi C, Kerwan A, Al-Jabir A, losifidis C, et al. The socio-economic implications of the coronavirus pandemic (COVID-19): a review. Int J Surg. 2020;78:185-93.

5. Pak A, Adegboye OA, Adekunle Al, Rahman KM, McBryde ES, Eisen DP Economic consequences of the COVID-19 outbreak: the need for epidemic preparedness. Front Public Health. 2020;8:241. 
6. Greece Coronavirus: 116,721 Cases and 3,092 Deaths - Worldometer. https:// www.worldometers.info/coronavirus/country/greece/. Accessed 8 Dec 2020

7. Ali I. COVID-19: Are we ready for the second wave? Disaster Med Public Health Prep. 2020;14(5):e16-e18.

8. Chirwa GC. "Who knows more, and why?" Explaining socioeconomic-related inequality in knowledge about HIV in Malawi. Scientific African. 2020;7:e00213.

9. Draft landscape of COVID-19 candidate vaccines. https://www.who.int/ publications/m/item/draft-landscape-of-covid-19-candidate-vaccines. Accessed 11 Sep 2020

10. COVID-19 vaccine tracker. https://www.raps.org/news-and-articles/newsarticles/2020/3/covid-19-vaccine-tracker. Accessed 11 Sep 2020.

11. Bloom BR, Nowak GJ, Orenstein W. "When Will We Have a Vaccine?" Understanding Questions and Answers about Covid-19 Vaccination. N Engl J Med. 2020;383:2202.

12. Neumann-Böhme S, Varghese NE, Sabat I, Barros PP, Brouwer W, van Exel J, et al. Once we have it, will we use it? A European survey on willingness to be vaccinated against COVID-19. Eur J Health Econ. 2020;21(7):977-82.

13. Thorneloe R, Wilcockson HE, Lamb M, Jordan CH, Arden M. Willingness to receive a COVID-19 vaccine among adults at high-risk of COVID-19: a UKwide survey. preprint. PsyArXiv. 2020. https://doi.org/10.31234/osf.io/fs9wk.

14. Smith TC. Vaccine rejection and hesitancy: a review and call to action. Open Forum Infect Dis. 2017;4. https://doi.org/10.1093/ofid/ofx146.

15. Vaccine hesitancy among healthcare workers and their patients in Europe: a qualitative study. Stockholm: ECDC; 2015. https://data.europa.eu/doi/10.2 900/425780. Accessed 11 Sep 2020

16. Blasi F, Aliberti S, Mantero M, Centanni S. Compliance with anti-H1N1 vaccine among healthcare workers and general population. Clin Microbiol Infect. 2012;18(Suppl 5):37-41.

17. Sypsa V, Livanios T, Psichogiou M, Malliori M, Tsiodras S, Nikolakopoulos I, et al. Public perceptions in relation to intention to receive pandemic influenza vaccination in a random population sample: evidence from a cross-sectional telephone survey. Euro Surveill. 2009;14:19437.

18. Ten health issues WHO will tackle this year. https://www.who.int/newsroom/spotlight/ten-threats-to-global-health-in-2019. Accessed 10 Sep 2020.

19. Dodd RH, Cvejic E, Bonner C, Pickles K, McCaffery KJ. Willingness to vaccinate against COVID-19 in Australia. Lancet Infect Dis. 2020. https://doi. org/10.1016/S1473-3099(20)30559-4.

20. Menon V, Thaker J. Aotearoa New Zealand public attitudes to COVID-19 vaccine. Wellington, New Zealand: Massey University; 2020.

21. Fisher KA, Bloomstone SJ, Walder J, Crawford S, Fouayzi H, Mazor KM. Attitudes Toward a Potential SARS-CoV-2 Vaccine: A Survey of U.S. Adults. Ann Intern Med. 2020;173:964.

22. Sherman SM, Smith LE, Sim J, Amlôt R, Cutts M, Dasch H, et al. COVID-19 vaccination intention in the UK: results from the COVID-19 vaccination acceptability study (CoVAccS), a nationally representative cross-sectional survey. Hum Vaccin Immunother. 2020:1-10. https://doi.org/10.1080/ 21645515.2020 .1846397

23. Sanche S, Lin YT, Xu C, Romero-Severson E, Hengartner N, Ke R. High contagiousness and rapid spread of severe acute respiratory syndrome Coronavirus 2. Emerg Infect Dis. 2020;26:1470-7.

24. Flaxman S, Mishra S, Gandy A, Unwin H, Coupland H, Mellan T, et al. Report 13: Estimating the number of infections and the impact of nonpharmaceutical interventions on COVID-19 in 11 European countries. Imperial College London. 2020. https://doi.org/10.25561/77731.

25. Nguyen $\mathrm{T}$, Henningsen $\mathrm{KH}$, Brehaut JC, Hoe E, Wilson K. Acceptance of a pandemic influenza vaccine: a systematic review of surveys of the general public. Infect Drug Resist. 2011;4:197-207.

26. Gidengil CA, Parker AM, Zikmund-Fisher BJ. Trends in risk perceptions and vaccination intentions: a longitudinal study of the first year of the H1N1 pandemic. Am J Public Health. 2012;102:672-9.

27. Tsoucalas G, Sgantzos M. The 2009 influenza a virus subtype H1N1 pandemic, a glance from Greece. Infez Med. 2016;24:259-64.

28. Teloniatis S, Tzortzi A, Behrakis P. Seasonal Influenza Vaccination Coverage in Greece in 2009 and 2014. Pneumon. 2017;30:41-8.

29. Peretti-Watel P, Seror V, Cortaredona S, Launay O, Raude J, Verger P, et al. A future vaccination campaign against COVID-19 at risk of vaccine hesitancy and politicisation. Lancet Infect Dis. 2020;20:769-70.

30. Dubé E, Laberge C, Guay M, Bramadat $P$, Roy $R$, Bettinger JA. Vaccine hesitancy. Hum Vaccin Immunother. 2013;9:1763-73.

31. McAteer J, Yildirim I, Chahroudi A. The VACCINES act: deciphering vaccine hesitancy in the time of COVID-19. Clin Infect Dis. 2020;71:703-5.
32. Bode L, Vraga EK. See something, say something: correction of Global Health misinformation on social media. Health Commun. 2018;33:1131-40.

33. van de Mortel TF. Faking it: Social desirability response bias in self-report research; 2008.
Ready to submit your research? Choose BMC and benefit from:

- fast, convenient online submission

- thorough peer review by experienced researchers in your field

- rapid publication on acceptance

- support for research data, including large and complex data types

- gold Open Access which fosters wider collaboration and increased citations

- maximum visibility for your research: over $100 \mathrm{M}$ website views per year

At $\mathrm{BMC}$, research is always in progress.

Learn more biomedcentral.com/submissions 